\title{
Erratum to: Roads to interdisciplinarity - working at the nexus among food systems, nutrition and health
}

\author{
1st annual Agriculture, Nutrition and Health (ANH) Academy Week, Addis Ababa \\ (Ethiopia), 20-24 June 2016
}

\author{
F. Picchioni ${ }^{1,2}$ - E. Aurino ${ }^{1,3}$ - L. Aleksandrowicz ${ }^{1,4} \cdot$ M. Bruce $^{1,5,6} \cdot$ S. Chesterman ${ }^{1,7}$. \\ P. Dominguez-Salas ${ }^{1,5,8} \cdot$ Z. Gersten $^{6,9} \cdot$ S. Kalamatianou ${ }^{1,4,6} \cdot$ C. Turner ${ }^{1,4} \cdot$ J. Yates $^{1,4,6}$
}

Published online: 23 May 2017

(C) Springer Science+Business Media Dordrecht and International Society for Plant Pathology 2017

Erratum to: Food Sec. (2017) 9:181-189

DOI 10.1007/s12571-017-0658-2

The article Roads to interdisciplinarity - working at the nexus among food systems, nutrition and health: 1st annual Agriculture, Nutrition and Health (ANH) Academy Week, Addis Ababa (Ethiopia), 20-24 June 2016, written by [F. Picchioni, E. Aurino, L. Aleksandrowicz, M. Bruce, S. Chesterman, P. Dominguez-Salas, Z. Gersten, S. Kalamatianou, C. Turner and J. Yates], was originally published Online First without open access. After publication in volume [9], issue [1], page [181-189] the author decided to opt for Open Choice and to

The online version of the original article can be found at http://dx.doi. org/10.1007/s12571-017-0658-2

F. Picchioni

f_picchioni@soas.ac.uk

1 Leverhulme Centre for Integrated Research on Agriculture and Health (LCIRAH), LIDC, 36 Gordon Square, London WC1H 0PD, UK

2 School of Oriental and African Studies (SOAS), London, UK

3 Imperial College, London, UK

4 London School of Hygiene and Tropical Medicine (LSHTM), London, UK

5 Royal Veterinary College (RVC), London, UK

6 Innovative Methods and Metrics for Agriculture and Nutrition Actions (IMMANA), London, UK

7 World Agroforestry Centre (ICRAF), Nairobi, Kenya

8 International Livestock Research Institute (ILRI), Nairobi, Kenya

9 Tufts University Friedman School of Nutrition Science and Policy, Boston, USA make the article an open access publication. Therefore, the copyright of the article has been changed to (C) The Author(s) [2016] and the article is forthwith distributed under the terms of the Creative Commons Attribution

[continuing for CC BY license] 6

4.0 International License (http://creativecommons. org/licenses/by/4.0/), which permits use, duplication, adaptation, distribution and reproduction in any medium or format, as long as you give appropriate credit to the original author(s) and the source, provide a link to the Creative Commons license, and indicate if changes were made. 